RUNNING HEAD:

17 *Corresponding author. Mailing address: Institute of Agrochemistry and Food 18 Technology (IATA-CSIC), Av. Agustín Escardino 7, Parque Científico, 46980 Paterna19 Valencia, Spain. Phone: +34 9639000 22, Fax: +34 9636363 01, E-mail: 20 mharos@iata.csic.es

21

22 This work was financially supported by grants AGL2006-09613/ALI, CSIC-200870I229 23 and Consolider Fun-C-Food CSD2007-00063 from the Ministry of Science and 24 Innovation, Spain (MICINN). The scholarship of J.M. Sanz Penella and the contract of 25 J.A. Tamayo Ramos from MICINN are greatly acknowledged. 
27 This investigation is aimed at developing a new cereal-based product, with increased 28 nutritional quality, by using Bifidobacterium pseudocatenulatum ATCC 27919 as starter

29 in whole wheat sourdough fermentation, and evaluating its performance. Four different 30 sourdough levels (5, 10, 15 and 20\% on flour basis) in bread dough formulation were 31 analysed. The effects of the use of bifidobacteria in sourdough bread were comparatively 32 evaluated with controls (yeast and/or chemically acidified sourdough with antibiotics). 33 The sourdough and dough fermentative parameters analysed were $\mathrm{pH}$, total titratable 34 acidity, D/L-lactic and acetic acids. Bread performance was evaluated by specific 35 volume, slice shape, crumb structure and firmness, crust and crumb colour, $\mathrm{pH}$, total 36 titratable acidity, and D/L-lactic and acetic acids, phytate and lower myo-inositol 37 phosphate contents. The sourdough breads showed similar technological quality to the 38 control sample, with the exception of specific bread volume (decreased from 2.46 to 2.22 $39 \mathrm{~mL} / \mathrm{g}$ ) and crumb firmness (increased from 2.61 to $3.18 \mathrm{~N}$ ). Sourdough inoculated with 40 bifidobacteria significantly increased the levels of organic acids in fermented dough and 41 bread. The Bifidobacterium strain contributed to the fermentation process, increasing 42 phytate hydrolysis during fermentation owing to the activation of endogenous cereal 43 phytase and its own phytase, resulting in bread with significantly lower phytate levels 44 (from 7.62 to $1.45 \mu \mathrm{mol} / \mathrm{g}$ of bread in dry matter). The inclusion of sourdough inoculated 45 with bifidobacteria made possible the formulation of whole wheat bread with positive 46 changes in starch thermal properties and a delay and decrease in amylopectin 47 retrogradation.

48

49 KEY WORDS: sourdough; Bifidobacterium; phytate-degrading enzyme; phytate; whole 50 wheat bread 
52 Cereal grains are grown in greater quantities and provide more food energy worldwide

53 than any other type of crop. Cereal foods produced and consumed in different ways are

54 an essential component of daily diet. Health experts advise that whole grains are a

55 healthy necessity in every diet, the consumption of at least half of the cereal servings as

56 whole grains being the recommendation for adults (Whole Grains Council, USA).

57 Epidemiological findings have indicated a protective role of whole grain foods against

58 several diseases. Medical evidence clearly shows that whole grains reduce risks of certain

59 diseases such as colorectal cancer, type 2 diabetes, coronary heart disease and obesity

60 (Pereira et al., 2002; Mellen et al., 2008). Cereal goods, especially whole grain products,

61 are source of fibre, vitamins, minerals and other biologically active compounds as

62 phenolic compounds, lignans, phytosterols, tocopherols, tocotrienols and phytic acid, and

63 processing may modify the amount and bioavailability of some of them (Slavin, 2004;

64 Katina et al., 2005). In fact, the whole grain or fractions of cereal grain could be modified

65 by sourdough fermentation to improve nutritional value or promote healthiness of cereal

66 by-products (Katina et al., 2005). The use of sourdough is a common practice in many

67 countries around the world. Sourdough fermentation can modify the flavour of products,

68 stabilize or increase levels of various bioactive compounds, retard starch bioavailability,

69 extend the shelf life of bread and improve mineral bioavailability (Katina et al., 2005).

70 Texture, taste and smell of bread are the main characteristics taken into account by

71 consumers to determine its quality. In this sense, there are numerous examples of

72 improved texture and palatability in sourdough fermentation processes due to peptide,

73 lipid and carbohydrate metabolism (Thiele et al., 2002; Gänzle et al., 2007). Although

74 sensory quality is the basis for any successful bakery product, consumers are aware of

75 nutrition/health interactions and consequently society demands healthier and more 
nutritious foods. The effect of sourdough and cereal fermentation could enhance delivery of nutrients to the bloodstream (Poutanen et al., 2009). As was mentioned above, sourdough has great potential to modify the digestibility of starch, lowering the glycemic index of the products mainly due to increased lactic and acetic acid levels (Katina et al., 2005; De Angelis et al., 2009). Whereas lactic acid lowers the rate of starch digestion in bread, acetic acid would delay the gastric emptying rate (Liljeberg et al., 1995; Liljeberg \& Björck, 1998).

On the other hand, phytic acid (myo-inositol $[1,2,3,4,5,6]$-hexakisphosphate, Ins $P_{6}$ ) or phytates (its salts), which are considered to be the major factor causing negative effects on mineral uptake in humans and animals, is a precursor of generation of bioactive compound (Fretzdorff \& Brümmer, 1992; Lopez et al., 2001; Nielsen et al., 2007; Haros et al., 2009). The phytates are capable to form complexes that strongly reduce the absorption of many minerals as iron, zinc, calcium, magnesium, manganese and copper (Lopez et al., 2002; Konietzny \& Greiner, 2003). However, the phytate hydrolysis decreases the negative effects on mineral absorption and generates lower myo-inositol phosphates that have been suggested to be compounds with specific biological activity and may positively affect human health (Shi et al., 2006; Haros et al., 2009). The phytase is the enzyme that catalyses the hydrolysis of $\operatorname{Ins} P_{6}$ to a mixture of myo-inositol pentakis, tetrakis-, tri-, di-, monophosphates (Ins $P_{5}, \operatorname{Ins} P_{4}, \operatorname{Ins} P_{3}, \operatorname{Ins} P_{2}$, Ins $P_{1}$, respectively) and orthophosphate. The reduction of Ins $P_{6}$ content during the bread making process depends on phytase action, which in turn depends on many factors including bran content, $\mathrm{pH}$, temperature, water content, particle size distribution, fermentation time, exogenous phytase addition and process (Haros et al., 2001; Lopez et al., 2002; Sanz Penella et al., 2008, 2009; Rosell et al., 2009). The cereal has an endogenous phytase, which its optimal $\mathrm{pH}$ of action is around 4.5 in wheat and rye doughs, hence the use of sourdough or 
101 acidified sponges increase the Ins $P_{6}$ hydrolysis (Fretzdorff \& Brummer, 1992; Lopez et

102 al., 2001; Reale et al., 2004). Phytases could be produced by a wide range of plants, 103 bacteria, and fungi; and some of them are commercially used for animal nutrition, 104 although are not considered of food grade (Haros et al., 2009). It was reported that strains 105 of Bifidobacterium show phytase activity, suggesting their possible utility in producing 106 bakery products (Haros et al., 2005; 2007). Sanz Penella et al. (2009) investigated the use 107 of bifidobacteria with high phytate-degrading activity as starter cultures in two 108 formulations of bread (100\% and $50 \%$ of whole wheat flour) resulting in breads with 109 significantly lower levels of phytates. Palacios et al. (2008) investigated the use of 110 Bifidobacterium strains as starter during long fermentation process of whole-wheat 111 dough, which showed a good adaptation to the dough ecosystem and contributed to 112 different acidification degrees promoting the phytate hydrolysis. Many new interesting 113 applications for sourdough still remain to be explored, such as the use of Bifidobacterium 114 starter cultures for improving phytate hydrolysis, or the production of organic acids and 115 novel bioactive compounds. This research is aimed at developing new cereal-based 116 products of increased nutritional quality and containing lower amounts of $\operatorname{Ins} P_{6}$, by using 117 bifidobacteria of human origin, Bifidobacterium pseudocatenulatum ATCC27919, as a 118 starter in whole wheat sourdough fermentation. 
121 Materials

122 Commercial Spanish whole wheat flour was purchased from the local market. The 123 characteristics of flour were $\left(\mathrm{g} \mathrm{kg}^{-1}\right.$ in dry matter): moisture $141.6 \pm 0.3$, protein $(\mathrm{N} \times 5.7)$

124 111.7 \pm 0.6 , lipids 17.6 \pm 0.2 , and ash 8.4 \pm 0.1 . Compressed yeast (Saccharomyces 125 cerevisiae, Levamax, Spain) was used as a starter for the bread making process, whereas 126 Bifidobacterium pseudocatenulatum ATCC 27919, originally isolated from faeces of 127 infants, was used as starter in sourdough fermentation.

129 Microbial growth conditions.

130 Bifidobacteria were grown in Garche broth in which inorganic phosphate $\left(\mathrm{K}_{2} \mathrm{HPO}_{4}\right.$ and $131 \mathrm{NaH}_{2} \mathrm{PO}_{4}$ ) was replaced by $0.74 \mathrm{~g} / \mathrm{L}$ phytic acid dipotassium salt (Sigma-Aldrich, St. 132 Louis, MO, USA) and 0.1 M 3-[N-Morpholino] propanesulphonic acid buffer (MOPS, 133 Sigma-Aldrich, St. Louis, MO, USA) (Haros et al., 2007). The medium was inoculated at $1345 \%(\mathrm{v} / \mathrm{v})$ with 18-hour old cultures, previously propagated under the same conditions. 135 Cultures were incubated at $37^{\circ} \mathrm{C}$ in anaerobic conditions (AnaeroGen ${ }^{\mathrm{TM}}$, Oxoid, 136 England) until the beginning of the stationary phase of growth ( 14-18 hours). Bacterial 137 cells were harvested by centrifugation $\left(10,000 \mathrm{x}\right.$ g, 15 min., $4{ }^{\circ} \mathrm{C}$, Sorvall RC-5B, DuPont 138 Instruments), washed twice and suspended in $0.085 \% \mathrm{NaCl}$ solution (Sanz Penella et al., 139 2009). The obtained cell suspensions were used to inoculate the sourdough. Microbial 140 counts in sourdough and dough samples were determined by plate count on selective 141 media. Sourdough and dough samples from each formulation (1 g) were homogenised 142 with $9 \mathrm{~mL}$ of peptone water (Scharlau Chemie, Barcelona, Spain), serially diluted and 143 plated on agar. Bifidobacteria counts were determined after sourdough incubation and 144 dough fermentation periods in Garche agar, using the double layer technique, after 
anaerobic incubation at $37^{\circ} \mathrm{C}$ for $48 \mathrm{~h}$ (Haros et al., 2005). Yeast counts were determined in Rose Bengal Agar (Scharlau Chemie, Barcelona, Spain) after aerobic incubation at 30 ${ }^{\circ} \mathrm{C}$ for $72 \mathrm{~h}$ (Sanz Penella et al., 2009).

\section{Bread-making process}

The control bread dough formula consisted of whole wheat flour (500 g), compressed yeast (2.5 \% flour basis), sodium salt (1.8 \% flour basis), tap water (up to optimum absorption, 500 Brabender Units, $65.0 \%)$ and ascorbic acid (0.01 \% flour basis). The ingredients were mixed for $4.5 \mathrm{~min}$, rested for $10 \mathrm{~min}$, divided (100 g), kneaded and then rested (15 min). Doughs were manually sheeted and rolled, proofed (up to optimum volume increase, at $28{ }^{\circ} \mathrm{C}, 85 \%$ relative humidity) and baked $\left(165^{\circ} \mathrm{C}, 30 \mathrm{~min}\right)$ according to Haros et al. (2001).

Whole wheat sourdough without yeast were prepared and added in five levels to bread doughs formula: 0, 5, 10, 15 and $20 \%$ in flour basis (Control, WDS-5, WDS-10, WDS15 and WDS-20, respectively). The sourdough formulation consisted in a mixture of

160 flour and water (1:2, v/v) with an inoculum $\sim 5.5 \times 10^{8}$ CFU of B. pseudocatenulatum per 161 gram of flour, incubated for 18 hours at $37^{\circ} \mathrm{C}$ in anaerobic conditions. The control acid sourdough consisted of the same formulation and conditions as described above without

163 the addition of Bifidobacterium strain, including a mixture of antibiotics at $1 \% \mathrm{v} / \mathrm{v}$

164 (Penicillin, $50 \mathrm{U} / \mathrm{mL}$; Streptomycin, $0.05 \mathrm{mg} / \mathrm{mL}$; Neomycin, $0.1 \mathrm{mg} / \mathrm{mL}$; and 165 Cycloheximide, $0.5 \mathrm{mg} / \mathrm{mL}$ from Sigma-Aldrich Steinheim, Germany). The control acid 166 sourdough $\mathrm{pH}$ was adjusted at 4.17 with a mixture of lactic and acetic acids $(1: 2 \mathrm{v} / \mathrm{v})$, to 167 reach the same $\mathrm{pH}$ of sourdough biologically acidified with using bifidobacteria. 168 Fermentation was monitored by measuring $\mathrm{pH}$, temperature and volume increase of the 169 dough at regular period times. After the fermentation step, doughs were baked in an 
170

171 (Sanz Penella et al., 2009).
173

174 175 determined hue angle $\left(h^{*}\right)$, chroma $\left(C^{*}\right)$ and total colour difference $\left(\Delta E^{*}\right)$ were

\section{Bread Performance}

The technological parameters analysed were: loaf specific volume $\left(\mathrm{cm}^{3} / \mathrm{g}\right)$, width/height ratio of the central slice or slice shape $(\mathrm{cm} / \mathrm{cm})$, moisture content $(\%)$ and crumb firmness, determined by a texture profile analysis using the Texture Analyser TA-XT Plus (Stable Micro Systems, Surrey, United Kingdom) (Sanz Penella et al., 2009). Each parameter was measured at least per triplicate.

Digital image analysis was used to measure the bread crumb structure. Images were previously squared at 240 pixels per cm with a flatbed scanner (HP ScanJet 4400C, Hewlett Packard, USA) supported by the HP PrecisionScan Pro 3.1 Software. Two 10 mm x 10 mm squares field of view of central slice (10 mm thick) of each of three loaves were used, thereby yielding 6 digital images per each baking. Data was processed using Sigma Scan Pro Image Analysis Software (version 5.0.0, SPSS Inc., USA). The crumb grain features chosen were: cell area/total area, $\mathrm{cm}^{2} / \mathrm{cm}^{2}$; wall area/total area, $\mathrm{cm}^{2} / \mathrm{cm}^{2}$; number of cells per $\mathrm{cm}^{2}$; and mean cell area, $\mathrm{mm}^{2}$ (Sanz Penella et al., 2009).

The tristimulus colour parameters $L^{*}$ (lightness), $a^{*}$ (redness to greenness), $b^{*}$ (yellowness to blueness) of the baked loaves (crumb and crust) were determined using a digital colorimeter (Chroma Meter CR-400, Konika Minolta Sensing, Japan), previously calibrated with the white plate supplied by the manufacturer. The instrument settings were illuminant $\mathrm{C}$, display $L^{*} a^{*} b^{*}$, and observer angle $10^{\circ}$. From the parameters

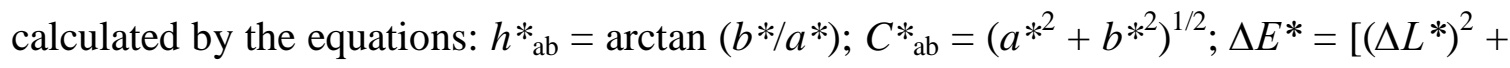


$\left.194\left(\Delta a^{*}\right)^{2}+\left(\Delta b^{*}\right)^{2}\right]^{1 / 2}$. Each sample was measured 18 times in different sample points to 195 minimize the heterogeneity produced by the bran.

196 Initial Ins $P_{6}$ concentration in whole wheat flour, $\operatorname{Ins} P_{6}$ residual amount and lower myo197 inositol phosphates generated after fermentation and baking in bread were measured by 198 using the high pressure liquid chromatographic method described by Türk and Sandberg 199 (1992), later modified by Sanz Penella et al. (2008).

200 Preliminary sensory analysis of fresh breads was performed by a panel of 20 non-trained 201 tasters, who usually consume whole wheat bread, using a simple scale of acceptation 202 (dislike very much, dislike, like, like very much).

204 Total titratable acidity (TTA) determination, D/L- lactic and acetic acids

205 Ten grams of sourdough, dough or bread, blended with $100 \mathrm{~mL}$ of acetone:water (5:95, $206 \mathrm{v} / \mathrm{v}$ ) under constant agitation, were titrated against $0.1 \mathrm{~N} \mathrm{NaOH}$ until a final $\mathrm{pH}$ of 8.5. 207 The results were expressed as the volume $(\mathrm{mL})$ of $\mathrm{NaOH} 0.1 \mathrm{~N}$ needed for titrating $10 \mathrm{~g}$ 208 of sourdough, fermented dough or bread. Concentrations of D-lactic acid, L-lactic acid 209 and acetic acid were analysed using the specific enzymatic methods of Boehringer 210 Mannheim/R-Biopharm by UV method (Polar Star Omega BMG LABTECH, Germany).

211 The results were expressed as $\mu$ moles of D/L lactic or acetic acid per gram of sourdough, 212 fermented dough or bread.

214 Differential scanning calorimetry (DSC) analysis

215 The thermal properties of starch flour during the baking of fermented dough 216 (gelatinization) and changes induced during the bread storage (amylopectin 217 retrogradation) were carried out on a calorimeter (DSC-7, Perkin-Elmer). Indium 218 (enthalpy of fusion $28.41 \mathrm{~J} / \mathrm{g}$, melting point $156.4{ }^{\circ} \mathrm{C}$ ) was used to calibrate the 
219 calorimeter. Fermented dough samples (30-40 mg) were weighted directly into DSC 220 stainless steel pans (LVC 0319-0218, Perkin-Elmer) and hermetically sealed (Quick221 Press, 0990-8467, Perkin-Elmer). Calorimeter scan conditions were used according to the 222 methodology described by Leon et al. (1997), later modified by Sanz-Penella et al. 223 (2010). Briefly, to simulate the temperature profile in the centre of the bread crumb 224 during baking, the samples were kept at $30{ }^{\circ} \mathrm{C}$ for $1 \mathrm{~min}$, were heated from 30 to $110{ }^{\circ} \mathrm{C}$ 225 at $11.7{ }^{\circ} \mathrm{C} / \mathrm{min}$, were kept at this temperature until $5 \mathrm{~min}$, and cooled to $30{ }^{\circ} \mathrm{C}$ at 50 $226{ }^{\circ} \mathrm{C} / \mathrm{min}$. To analyse amylopectin retrogradation, heated-cooled pans were stored at $4{ }^{\circ} \mathrm{C}$ 227 for $0,1,2,4,7,10$ and 15 days, and heated again in the calorimeter from 30 to $110{ }^{\circ} \mathrm{C}$, at $22810{ }^{\circ} \mathrm{C} / \mathrm{min}$ (Sanz-Penella et al., 2010). An empty pan was used as a reference and three 229 replicates of each sample were analysed.

230 The parameters recorded were onset temperature $\left(T_{0}\right)$, peak temperature $\left(T_{p}\right)$ and 231 conclusion temperature $\left(\mathrm{T}_{\mathrm{c}}\right)$ of gelatinization and retrogradation. Straight lines were 232 drawn between $T_{o}$ and $T_{c}$ and the enthalpies associated with starch gelatinisation and 233 retrogradation ( $\Delta H_{\mathrm{g}}$ and $\Delta H_{\mathrm{r}}$, respectively) were calculated as the area enclosed between 234 the straight line and the endotherm curve. The enthalpies were expressed in Joules per 235 grams of dry matter.

237 Statistical analysis

238 Multiple sample comparison of the means and Fisher's least significant differences 239 (LSD) were applied to establish statistical significant differences between treatments. All 240 statistical analyses were carried out with the software Statgraphics Plus 7.1 (Bitstream, 241 Cambridge, MN) and differences were considered significant at $p<0.05$. 
Characteristics of sourdough

246 The sourdough inoculated with bifidobacteria used in this study became more acidic at

247 the end of the incubation period (from initial $\mathrm{pH} 5.4$ to final $\mathrm{pH} 4.2$ ) owing to

248 fermentative activity of the microbial metabolism. As observed in the literature, the

249 values of $\mathrm{pH}$ in ripe sourdoughs using typical starters such as Lactobacillus

250 sanfranciscensis, Lactobacillus plantarum and/or Lactobacillus brevis can vary between

2513.5 and 4.3, depending on the type of flour, the process and the starter cultures used

252 (Collar et al., 1994; De Angelis et al., 2009; Thiele et al., 2002; Robert et al., 2006).

253 During the incubation period there was a considerable production of organic acids 254 (mainly acetic and lactic acids) reaching TTA values around $17.0 \mathrm{~mL}$, with the 255 production of lactic acid exclusively in its levorotatory form (Table 1). Robert et al. 256 (2006) reported lower values of TTA in sourdoughs inoculated with L. plantarum or 257 Leuconostoc sp. In the current study the molar ratio between lactic and acetic acids was 258 0.37. It should be pointed out that acetic acid production is greater than lactic acid 259 production in bifidobacteria. This value corresponds to typical molar ratios found as the 260 result of sugar catabolism in bifidobacteria, 0.40-0.70, mainly depending on the strain 261 and the sugar (Van der Meulen et al., 2006). Metabolism of carbohydrates varies 262 depending on the species of Bifidobacterium, and even the strains, the type of soluble 263 sugars and the processing conditions. The metabolite production for $B$. 264 pseudocatenulatum after growing in synthetic medium containing different energy 265 sources showed a molar ratio between 0.38 and 0.74 (results not shown). Although the 266 optimum in industrial sourdough fermentation of wheat is considered around 2.5 (Röcken 267 1996; Hammes \& Gänzle, 1998), this value can vary over wider ranges (Barber et al., 268 1991). Lactic and acetic acid production was considered the main reason for the decrease 
269 in the value of $\mathrm{pH}$ after sourdough fermentation. Lactic acid bacteria (LAB) counts

270 showed $4.0 \times 10^{9} \mathrm{CFU}$ per gram of flour after the incubation period, which represented a

271 considerable increase from the initial value. The LAB population was in the range of

272 counts found in mature sourdoughs (Hammes et al. 2005; Robert et al., 2006). The pH

273 value reached at the end of sourdough fermentation and the colony counts indicated that

274 the inoculated bifidobacterial strain could adapt to the dough environment, increasing its 275 viability.

276

277 Characteristics of fermented dough

278 The inclusion of sourdough in the bread formulation caused a significant decrease in the 279 dough $\mathrm{pH}$, from 5.38 to 4.57, as was expected (Table 1). However, the dough $\mathrm{pH}$ 280 remained unchanged during the yeast fermentation process until the optimum volume 281 increase was reached. Similar pH values were found by Collar et al. (1994) when 282 sourdough was added in a proportion of between 10 and $25 \%$ on flour basis. Dough 283 volume showed a constant increase during the fermentation period, reaching a maximum 284 after approximately 60 minutes at $28{ }^{\circ} \mathrm{C}$. The presence of sourdough in the bread 285 formulation did not significantly modify the optimum dough volume. However, the 286 addition of sourdough to the formulation significantly increased the LAB counts (from $2872.2 \times 10^{4} \mathrm{CFU} / \mathrm{g}$ to $1.1 \times 10^{7} \mathrm{CFU} / \mathrm{g}$, control and WDS-20 samples, respectively), 288 whereas the yeast counts remained almost constant (3.7-5.0 × 10 $\left.{ }^{7} \mathrm{CFU} / \mathrm{g}\right)$. These LAB 289 and yeast counts were consistent with previous reports shown by other authors (Palacios 290 et al., 2006, 2008). TTA values in fermented dough ranged from 4.60 to 9.23, showing a 291 constant and significant increase mainly due to the production of lactic and acetic acid 292 during sourdough fermentation (Table 1). This highlights the considerable acidic 293 production of the Bifidobacterium strain used in this study, which may be important for 
enhancing flavour and delaying bread staling. The D-lactic acid content decreased with the rise in the sourdough percentage added to the formulation, whereas the L-lactic and acetic acids presented a significant increase. The molar ratio between the D/L-lactic and acetic acids remained between 0.45 and 0.47 in all formulations with sourdough inoculated with bifidobacteria (Table 1). L. plantarum, L. brevis and Leuconostoc sp. were reported to produce greater amounts of lactic acid (5.5-13.3 $\mu \mathrm{mol} / \mathrm{g})$ than the culture used in this study, and lower amounts of acetic acid (1.66-5.82 $\mu \mathrm{mol} / \mathrm{g})$, in fermented dough made with sourdough (Collar et al., 1994; Robert et al., 2006).

\section{Acidic characteristics of bread}

TTA values in the bread were recorded from 4.19 to 10.60 (Table 1). These results were in the range found by other researcher in bread with sourdough inoculated with lactobacilli (Katina et al., 2009), although this parameter could vary over a wider range. The D/L-lactic and acetic acids showed the same tendency as was found in the fermented dough: the amount of D-lactic acid decreased with the increase in sourdough in the formulation, whereas the L-lactic and acetic acids showed an opposite behaviour (Table 1). L. plantarum and L. brevis resulted in lower acetic acid production $(1.2-2.3 \mu \mathrm{mol} / \mathrm{g})$ than the levels found in this study, whereas the amount of lactic acid was significantly higher, reaching values up to $40.9 \mu \mathrm{mol} / \mathrm{g}$ (Collar et al., 1994). The molar ratio between D/L-lactic and acetic acids registered an increase from 0.91 in the control sample to 1.291.45 with the addition of $15-20 \%$ of sourdough in the bread formula. During the breadmaking process there is a weight loss, $95 \%$ of which is due to water evaporation and 5\% due to organic acid loss, mainly in crust and outside crumb of the bread, the loss of acetic acid during baking being greater than that of lactic acid (Spicher, 1983). This greater loss of acetic acid was responsible for the increase in the molar ratio between the 
D/L-lactic and acetic acids of the bread compared to the values recorded in the fermented

320 dough. It is important to note that the increase in the amount of these organic acids

321 caused by the use of sourdough has been shown to lower the glycemic index of bread

322 products (Liljeberg et al., 1995; Liljeberg \& Björck, 1998).

\section{Bread performance}

325 The effect of the addition of sourdough on bread quality was analysed (Table 2). In

326 general, technological parameters did not show significant differences between samples.

327 The loaf moisture ranged between 34.74 and 36.04 without significant changes. The 328 sample with $20 \%$ sourdough content (WDS-20) showed a significantly lower loaf 329 specific volume than the control, whereas the slice shape remained without significant 330 differences, but tended to decrease (Table 2). There is considerable consensus with 331 regard to the positive effects of the addition of sourdough on bread volume and crumb 332 structure (Arendt et al., 2007). Despite this, Collar et al. (1994) developed lower volume 333 breads when using a high percentage of sourdough with L. plantarum and L. brevis as 334 starters. The acidification of the sourdough and partial acidification of the bread dough 335 impact on structure-forming components like gluten and starch. During incubation of 336 sourdough and dough fermentation, biochemical changes occur in the carbohydrate and 337 protein components of flour owing to the action of microbial and endogenous enzymes.

338 The possible proteolytic activity associated with the Bifidobacterium strain, which would 339 take place during the incubation period of sourdough incubation and dough fermentation, 340 would attack gluten-associated proteins and weaken the gluten network, leading to breads 341 with a lower specific volume. This proteolytic activity has been observed in several 342 lactobacilli strains found in different sourdoughs, which might contribute an 343 improvement in bread flavour (Rollan et al., 2005). 
344 The crumb textural profile of samples to which sourdough had been added showed no 345 significant difference compared with the control (data not shown). However, the crumb 346 firmness showed a constant increase from 2.61 in the control sample to $3.18 \mathrm{~N}$ in the 347 formulation with $20 \%$ sourdough (Table 2). Increased firmness with addition of 348 sourdough was at least partly due to the lower specific volume found in these samples. 349 Softer breads were found after the inclusion of mature sourdough in the bread 350 formulation, which might depend on the number of stages used in sourdough preparation 351 (Barber et al., 1991).

352 The parameters that describe crumb grain features did not show any significant 353 difference between samples (Table 2). Despite this, the cell area and number of cells 354 showed a slight correlation, with the value decreasing when a greater percentage of 355 sourdough was added to the formulation (15-20\%). The technological parameters (loaf 356 specific volume, width/height ratio and firmness) could corroborate this tendency (Figure 357 1). However, although these differences were statistically significant, they were 358 unimportant in the sensory analysis (results not shown). The values of the mean cell area 359 ranged from 0.95 to 1.32, with no differences appearing between breads made with 360 sourdough and the control (without sourdough).

361 The effect of the addition of sourdough inoculated with bifidobacteria on the crust and 362 crumb colour was determined (Table 3). Generally, the sourdough did not present 363 significant changes in the crust or crumb colour of the bread in comparison to the control. 364 The total colour difference in bread crust and crumb, which represents the total colour 365 difference between the samples with sourdough and the control sample, was less than 5 366 units (from 0.67 to 3.16), indicating that no differences were detectable by visual 367 observation. So, although some significant changes were recorded in a few colour 368 parameters, they were not perceptible to consumers by visual observation (Figure 1). 
371 sourdough showed the lowest degree of acceptance, mainly because of its higher acidity,

372 being accepted by $40 \%$ of the tasters.

Degradation of phytate and generation of lower myo-inositol phosphates

The phytate content in the control bread was reduced by $28 \%$ over baseline in the flour

(Table 4). Its reduction and the generation of lower myo-inositol phosphates were mainly due to endogenous cereal phytase, since it is known that phytates decrease during the

378 breadmaking process as a consequence of the activity of this enzyme (Haros et al., 2001).

379 The addition of sourdough to the bread formula produced a significant decrease in the amount of $\operatorname{Ins} P_{6}$. This reduction was greater when the amount of sourdough increased in 381 the formulation, from $7.62 \mu \mathrm{mol} / \mathrm{g}$ (control sample) to $1.45 \mu \mathrm{mol} / \mathrm{g}$ (WDS-20). Leenhardt 382 et al. (2005) reported that slight acidification of dough (pH 5.5) with sourdough 383 containing $L$. brevis allowed a significant phytate breakdown, up to $70 \%$ of the initial 384 flour content compared to $40 \%$ in the control sample. Sourdough fermentation with a multi-species starter including L. plantarum and L. mesenteroides was more efficient 386 than yeast fermentation in reducing phytate content in whole wheat bread, reaching 387 values around $25 \%$ hydrolysis after 1 hour of fermentation (Lopez et al. 2001).

388 The acidified control, which was supplemented by the amount of acids (lactic and acetic 389 acids) required to mimic the $\mathrm{pH}$ reached by sourdough fermented by bifidobacteria, 390 showed an intermediate concentration of $\operatorname{Ins}_{6}$ (Table 4). This indicated that the 391 endogenous phytase was also activated by the reduction of $\mathrm{pH}$ during the fermentation 392 period. As mentioned above, the addition of sourdough produced a decrease in $\mathrm{pH}$ from 3935.38 (control dough) to 4.57 (WDS-20). A similar observation was obtained in the dough 
with $20 \%$ acid control sourdough, which reached a pH of 4.58. Given that endogenous

395 phytase acts during the breadmaking process and its optimum $\mathrm{pH}$ is around 4.1-4.5, 396 acidification of dough due to microbial metabolism could activate this enzyme 397 (Leenhardt et al., 2005). However, hydrolysis of Ins $P_{6}$ of samples containing $20 \%$ 398 sourdough inoculated with bifidobacteria (WDS-20) was significantly higher than 399 samples with chemically acidified sourdough in the same percentage of addition. This 400 suggests that the additional hydrolysis was due to phytase activity of $B$. 401 pseudocatenulatum, which has already been studied in previous investigations (Haros et 402 al., 2005, 2009; Sanz Penella et al., 2009).

403 The amount of lower myo-inositol phosphates showed a significant increase with the 404 addition of sourdough inoculated with the Bifidobacterium strain, mainly in the amounts 405 of $\operatorname{Ins} P_{4}$ and $\operatorname{Ins} P_{3}$. The intake of breads with a higher amount of lower myo-inositol 406 phosphate could have positive effects on human health by increasing the bioavailability 407 of minerals or as a result of their bioactive functions in the body, especially Ins $P_{3}$ (Shi et 408 al., 2006; Haros et al., 2009). Although the Bifidobacterium strain showed phytase 409 activity, cereal activity was the predominant activity compared to the microbial enzyme 410 during the breadmaking process. The additional Ins $P_{6}$ hydrolysis by Bifidobacterium 411 during sourdough incubation and dough fermentation might change the myo-inositol 412 phosphate profile in the final product (results not shown).

414 Thermal parameters of wheat starch in bread

415 The differential scanning calorimeter was used as an oven to bake the bread dough inside 416 the capsules. This procedure allows determination of the thermal behaviour of wheat 417 starch during the baking process using hermetic capsules. When the temperature of the 418 fermented dough increased from 30 to $110{ }^{\circ} \mathrm{C}$, the thermograms obtained from all the 
420 to the gelatinization process of the amorphous phase of the starch. It was observed 421 between $67.3^{\circ} \mathrm{C}$ and $80.8{ }^{\circ} \mathrm{C}$, reaching enthalpy values from 0.45 to $0.57 \mathrm{~J} / \mathrm{g}$ (control and 422 WDS-20, respectively). The addition of sourdough produced a slight but significant 423 decrease in onset temperature $\left(67.4{ }^{\circ} \mathrm{C}\right)$ compared to the control dough $\left(68.1^{\circ} \mathrm{C}\right)$, 424 although there were no significant differences between treatments adding from 5 to $20 \%$ 425 of sourdough. With regard to the peak temperature $\left(T_{p}\right)$, all samples remained constant 426 with no significant differences. A similar observation was recorded in the conclusion 427 temperature $\left(T_{c}\right)$. Regarding the enthalpy of gelatinization, the addition of sourdough 428 provided a slight increase, from $0.46 \mathrm{~J} / \mathrm{g}$ to $0.57 \mathrm{~J} / \mathrm{g}$ (control and WDS-20, respectively). 429 This increase was significant compared to the control sample when 15-20 \% sourdough 430 was added to the dough (WSD-15 and WSD-20). Both samples had higher $\Delta H_{\mathrm{g}}$ values 431 and similar gelatinization temperatures compared with other samples, suggesting better 432 starch hydration during the period of fermentation (Leon et al., 1997).

433 The effect of the addition of sourdough on the retrogradation kinetics during storage was 434 analysed (Figure 2). During the first days of storage no significant differences between 435 samples were found. After the seventh day there was a significant reduction in enthalpy 436 with the increase in the amount of sourdough in the formulation (Figure 2). After 15 days 437 of storage, retrogradation enthalpy achieved an asymptotic behaviour, reaching a value of $4381.44 \mathrm{~J} / \mathrm{g}$ (control sample), whereas the samples with sourdough showed significantly 439 lower values (between 1.24 and $1.00 \mathrm{~J} / \mathrm{g}$ ). The phenomenon of retrogradation is closely 440 related to the ageing of bread (Barcenas et al., 2003a), which depends on the formulation, 441 among other factors. The inclusion of sourdough in the breadmaking process could delay 442 ageing, which is related to the physical changes that take place in starch retrogradation 443 (Barcenas et al., 2003b). 


\section{CONCLUSIONS}

446 Sourdough inoculated with bifidobacteria could make possible the formulation of whole

447 wheat bread that allows an increase in phytate hydrolysis, enhancement of organic acid 448 levels that modify starch digestibility, and a delay/decrease in amylopectin 449 retrogradation, with high acceptance by consumers. Bifidobacterium strains are 450 GRAS/QPS microorganisms (Generally Regarded as Safe/Qualified Presumption of 451 Safety), do not significantly affect bread performance and increase its nutritional value, 452 and could therefore be used as starters in sourdough formulations, producing a quality 453 similar to the control sample. 


\section{REFERENCES}

458 Arendt EK, Ryan LAM \& Dal Bello F (2007) Impact of sourdough on the texture of 459 bread. Food Microbiology, 24, 165-174.

460 Barber S, Báguena R, Benedito de Barber C \& Martinez-Anaya MA (1991) Evolution of

461 biochemical and rheological characteristics and breadmaking quality during a multistage 462 wheat sour dough process. Zeitschrift für Lebensmittel-Untersuchung und -Forschung, 463 192, 46-52.

464 Barcenas ME, Haros M, Benedito C \& Rosell CM (2003a) Effect of freezing and frozen 465 storage on the staling of part-baked bread. Food Research International, 36, 863-869.

466 Barcenas ME, Haros M \& Rosell CM (2003b) An approach to studying the effect of 467 different bread improvers on the staling of pre-baked frozen bread. European Food 468 Research and Technology, 218, 56-61.

469 Collar C, Benedito de Barber C \& Martinez-Anaya MA (1994) Microbial sourdoughs 470 influence acidification properties and breadmaking potential of wheat dough. Journal of 471 Food Science, 59, 629-633.

472 De Angelis M, Damiano N, Rizzello CG, Cassone A, Di Cagno R \& Gobbetti M (2009) 473 Sourdough fermentation as a tool for the manufacture of low-glycemic index white wheat 474 bread enriched in dietary fibre. European Food Research and Technology, 229, 593-601.

475 Fretzdorff B \& Brümmer JM (1992) Reduction of phytic acid during breadmaking of 476 whole-meal breads. Cereal Chemistry, 69, 266-270.

477 Gänzle MG, Vermeulen N \& Vogel RF (2007) Carbohydrate, peptide and lipid 478 metabolism of lactic acid bacteria in sourdough. Food Microbiology, 24, 128-138. 
479 Hammes WP \& Gänzle MG (1998) Sourdough breads and related products. In: Woods 480 (ed) Microbiology of Fermented Foods, pp 199-216. Blackie Academic and Professional, 481 London, UK.

482 Hammes WP, Brandt MJ, Francis KL, Rosenheim J, Seitter MFH \& Vogelmann SA 483 (2005) Microbial ecology of cereal fermentations. Trends in Food Science and 484 Technology, 16, 4-11.

485 Haros M, Rosell CM \& Benedito C (2001) Use of fungal phytase to improve 486 breadmaking performance of whole wheat bread. Journal of Agricultural and Food 487 Chemistry, 49, 5450-5454.

488 Haros M, Bielecka M \& Sanz Y (2005) Phytase activity as a novel metabolic feature in 489 Bifidobacterium. FEMS Microbiology Letters, 247, 231-239.

490 Haros M, Bielecka M, Honke J \& Sanz Y (2007) Myo-inositol hexakisphosphate 491 degradation by Bifidobacterium infantis. International Journal of Food Microbiology, 492 117, 76-84.

493 Haros M, Carlsson N-G, Almgrem A, Larsson Alminger M, Sandberg A-S \& Andlid T 494 (2009) Phytate degradation by human gut isolated Bifidobacterium pseudocatenulatum 495 ATCC27919 and its probiotic potential. International Journal of Food Microbiology, 135, $496 \quad 7-14$.

497 Katina K, Arendt E, Liukkonen KH, Autio K, Flander L \& Poutanen K (2005) Potential 498 of sourdough for healthier cereal products. Trends in Food Science and Technology, 16, $499 \quad 104-112$.

500 Katina K, Maina NH, Juvonen R, Flander L, Johansson L, Virkki L, Tenkanen M \& 501 Laitila A (2009) In situ production and analysis of Weissella confusa dextran in wheat 502 sourdough. Food Microbiology, 26, 734-743. 
503 Konietzny U \& Greiner R (2003) Encyclopedia of Food Science and Nutrition (2 ${ }^{\text {nd }}$ ed), 504 pp 4555-4563. Elsevier, London, UK.

505 Leenhardt F, Levrat-Verny MA, Chanliaud E \& Remesy C (2005) Moderate decrease of $506 \mathrm{pH}$ by sourdough fermentation is sufficient to reduce phytate content of whole wheat 507 flour through endogenous phytase activity. Journal of Agricultural and Food Chemistry, 508 53, 98-102.

509 Leon A, Duran E \& Benedito de Barber C (1997) A new approach to study starch 510 changes occurring in the dough-baking process and during bread storage. Zeitschrift für 511 Lebensmittel-Untersuchung und -Forschung A - Food Research and Technology, 204, $512 \quad 316-320$.

513 Liljeberg H, Lönner C \& Björck I (1995) Sourdough fermentation or addition of organic 514 acids or corresponding salts to bread improves nutritional properties of starch in healthy 515 humans. Journal of Nutrition, 125, 1503-1511.

516 Liljeberg H \& Björck I (1998) Delayed gastric emptying rate may explain improved 517 glycaemia in healthy subjects to a starchy meal with added vinegar. European Journal of 518 Clinical Nutrition, 52, 368-371.

519 Lopez HW, Krespine V, Guy C, Messager A, Demigne C \& Remesy C (2001) Prolonged 520 fermentation of whole wheat sourdough reduces phytate level and increases soluble 521 magnesium. Journal of Agricultural and Food Chemistry, 49, 2657-2662.

522 Lopez HW, Leenhardt F, Coudray C \& Remesy C (2002) Minerals and phytic acid 523 interactions: is it a real problem for human nutrition? International Journal of Food 524 Science and Technology, 37, 727-739. 
525 Mellen P, Walsh T \& Herrington D (2008) Whole grain intake and cardiovascular 526 disease: a meta-analysis. Nutrition Metabolism and Cardiovascular Diseases, 18, 283527290.

528 Nielsen MM, Damstrup ML, Dal Thomsen A, Rasmussen SK \& Hansen A (2007) 529 Phytase activity and degradation of phytic acid during rye bread making. European Food 530 Research and Technology, 225, 173-181.

531 Palacios MC, Sanz Y, Haros M \& Rosell CM (2006) Application of Bifidobacterium 532 strains to the breadmaking process. Process Biochemistry, 41, 2434-2440.

533 Palacios MC, Haros M, Sanz Y \& Rosell CM (2008) Selection of phytate-degrading 534 human bifidobacteria and application as starter cultures in whole-wheat dough 535 fermentation. Food Microbiology, 25, 169-176.

536 Pereira M, Jacobs D, Pins J, Raatz S, Gross M, Slavin J \& Seaquist E (2002) Effect of 537 whole grains on insulin sensitivity in overweight hyperinsulinemic adults. American 538 Journal of Clinical Nutrition, 75, 848-855.

539 Poutanen K, Flander L \& Katina K (2009) Sourdough and cereal fermentation in a 540 nutritional perspective. Food Microbiology, 26, 693-699.

541 Reale A, Mannina L, Tremonte P, Sobolev AP, Succi M, Sorrentino E \& Coppola R 542 (2004) Phytate degradation by Lactic Acid Bacteria and Yeasts during the wholemeal 543 dough fermentation: A P-31 NMR study. Journal of Agricultural and Food Chemistry, 544 52, 6300-6305.

545 Robert H, Gabriel V, Lefebvre D, Rabier P, Vayssier Y \& Fontagne-Faucher C (2006)

546 Study of the behaviour of Lactobacillus plantarum and Leuconostoc starters during a 547 complete wheat sourdough breadmaking process. LWT-Food Science and Technology, $548 \quad 39,256-265$. 
549 Röcken W (1996) Applied aspects of sourdough fermentation. Advances in Food 550 Science, 18, 212-216.

551 Rollan G, De Angelis M, Gobbetti M \& De Valdez GF (2005) Proteolytic activity and 552 reduction of gliadin-like fractions by sourdough lactobacilli. Journal of Applied 553 Microbiology, 99, 1495-1502.

554 Rosell CM, Santos E, Sanz Penella JM \& Haros M (2009) Wholemeal wheat bread: A 555 comparison of different breadmaking processes and fungal phytase addition. Journal of 556 Cereal Science, 50, 272-277.

557 Sanz Penella JM, Collar C \& Haros M (2008) Effect of wheat bran and enzyme addition 558 on dough functional performance and phytic acid levels in bread. Journal of Cereal 559 Science, 48, 715-721.

560 Sanz Penella JM, Tamayo Ramos JA, Sanz Y \& Haros M (2009) Phytate reduction in 561 bran-enriched bread by phytase-producing Bifidobacteria. Journal of Agricultural and 562 Food Chemistry, 57, 10239-10244.

563 Sanz-Penella JM, Wronkowska M, Soral-Smietana M, Collar C \& Haros M (2010) 564 Impact of the addition of resistant starch from modified pea starch on dough and bread 565 performance. European Food Research and Technology, 231, 499-508.

566 Shi Y, Azab AN, Thompson MN \& Greenberg ML (2006) Inositol phosphates and 567 phosphoinositides in health and disease. In: Majumder \& Biswas (ed) Biology of 568 Inositols and Phosphoinositides, pp 265-292. Springer Press, Subcellular Biochemistry.

569 Slavin J (2004) Whole grains and human health. Nutrition Research Reviews, 17, 99570110.

571 Spicher G (1983) Baked goods. In: Rehm \& Reed (ed) Biotechnology. Food and feed 572 production with microorganisms, pp 1-115. Verlag Chemie, Weinheim, Germany. 
573 Thiele C, Gänzle MG \& Vogel RF (2002) Contribution of sourdough lactobacilli, yeast 574 and cereal enzymes to the generation of amino acids in dough relevant for bread flavour. 575 Cereal Chemistry, 79, 45-51.

576 Türk M \& Sandberg AS (1992) Phytate degradation during breadmaking - effect of 577 phytase addition. Journal of Cereal Science, 15, 281-294.

578 Van der Meulen R, Adriany T, Verbrugghe K \& De Vuyst L (2006) Kinetic analysis of 579 bifidobacterial metabolism reveals a minor role for succinic acid in the regeneration of $580 \mathrm{NAD}^{+}$through its growth-associated production. Applied and Environmental 581 Microbiology, 72, 5204-5210. 
585 Figure 1. Aspect of the loaf, central slice and crumb image of bread. Bread formulation 586 WDS-5, WDS-10, WDS-15 and WDS-20: wheat dough with 5, 10, 15 and 20\% of 587 sourdough inoculated with bifidobacteria, respectively.

Figure 2. Effect of sourdough addition on the amylopectin retrogradation during baked 590 dough aging. Bread formulation WDS-5, WDS-10, WDS-15 and WDS-20: wheat dough 591 with 5, 10, 15 and 20\% of sourdough inoculated with bifidobacteria, respectively.

Table 1. Values of the total titratable acidity (TTA) and concentration of organic acids of sourdough, fermented dough and whole wheat bread ${ }^{\mathrm{a}}$

595

Table 2. Technological parameters and crumb structure of whole wheat bread ${ }^{a}$

Table 3. Effect of addition of sourdough inoculated with bifidobacteria in crust and 599 crumb colour of whole wheat bread ${ }^{\mathrm{ab}}$

600

601 Table 4. Effect of sourdough addition on myo-inositol phosphates content in whole

602 wheat bread ${ }^{\mathrm{a}}$

603

604

605 


\begin{tabular}{|c|c|c|c|c|c|}
\hline \multirow[t]{2}{*}{ Sample } & \multirow[t]{2}{*}{ pH } & TTA mL & \multicolumn{2}{|c|}{ D-Lactic acid L-Lactic acid } & \multirow{2}{*}{$\begin{array}{l}\text { Acetic acid } \\
\qquad \mu \mathrm{mol} / \mathrm{g}\end{array}$} \\
\hline & & $0.1 \mathrm{~N} \mathrm{NaOH}$ & $\mu \mathrm{mol} / \mathrm{g}$ & $\mu \mathrm{mol} / \mathrm{g}$ & \\
\hline \multicolumn{6}{|c|}{ Sourdough $^{b}$} \\
\hline Sourdough & $4.17 \pm 0.01$ & $17.24 \pm 1.77$ & n.d. & $25.23 \pm 2.16$ & $68.16 \pm 1.16$ \\
\hline \multicolumn{6}{|c|}{ Dough $^{c}$} \\
\hline Control & $5.38 \pm 0.04 a$ & $4.60 \pm 0.05 a$ & $0.96 \pm 0.10 \mathrm{a}$ & $1.83 \pm 0.87 \mathrm{a}$ & $2.51 \pm 0.05 a$ \\
\hline WDS-5 & $5.15 \pm 0.16 b$ & $5.91 \pm 0.55 b$ & $0.73 \pm 0.03 b$ & $4.26 \pm 0.15 b$ & $10.66 \pm 1.07 \mathrm{~b}$ \\
\hline WDS-10 & $4.79 \pm 0.35 c$ & $7.62 \pm 0.99 \mathrm{c}$ & $0.47 \pm 0.08 \mathrm{c}$ & $6.12 \pm 0.43 b$ & $14.74 \pm 1.55 c$ \\
\hline WDS-15 & $4.76 \pm 0.16 \mathrm{c}$ & $8.21 \pm 0.63 c d$ & $0.30 \pm 0.11 c$ & $8.84 \pm 0.86 c$ & $19.97 \pm 0.87 \mathrm{~cd}$ \\
\hline WDS-20 & $4,57 \pm 0.11 \mathrm{c}$ & $9.23 \pm 0.32 d$ & $0.05 \pm 0.06 \mathrm{~d}$ & $10.55 \pm 0.54 d$ & $23.53 \pm 0.24 d$ \\
\hline
\end{tabular}

\section{Bread $^{\mathbf{b}}$}

\begin{tabular}{lccccc}
\hline Control & $5,72 \pm 0.06 \mathrm{a}$ & $4.19 \pm 0.16 \mathrm{a}$ & $0.57 \pm 0.10 \mathrm{a}$ & $1.46 \pm 0.19 \mathrm{a}$ & $2.23 \pm 0.87 \mathrm{a}$ \\
WDS-5 & $5,50 \pm 0.07 \mathrm{ab}$ & $5.74 \pm 0.14 \mathrm{~b}$ & $0.39 \pm 0.18 \mathrm{a}$ & $7.88 \pm 1.11 \mathrm{~b}$ & $8.61 \pm 0.43 \mathrm{~b}$ \\
WDS-10 & $5,17 \pm 0.32 \mathrm{bc}$ & $7.59 \pm 0.31 \mathrm{c}$ & $0.18 \pm 0.08 \mathrm{a}$ & $9.78 \pm 1.60 \mathrm{~b}$ & $8.75 \pm 0.79 \mathrm{~b}$ \\
WDS-15 & $5,12 \pm 0.12 \mathrm{c}$ & $9.21 \pm 0.16 \mathrm{~d}$ & n.d. & $13.63 \pm 0.32 \mathrm{c}$ & $9.39 \pm 1.60 \mathrm{~b}$ \\
WDS-20 & $4,96 \pm 0.06 \mathrm{c}$ & $10.60 \pm 0.41 \mathrm{e}$ & n.d. & $15.35 \pm 1.22 \mathrm{c}$ & $11.93 \pm 1.40 \mathrm{~b}$
\end{tabular}

607 n.d.: not detected, TTA: Total titratable acidity; Bread formulations WDS-5, WDS-10, WDS-15 and

608 WDS-20: wheat dough with 5, 10, 15 and 20\% of sourdough inoculated with bifidobacteria, respectively.

609 Mean, ${ }^{b} n=8 ;{ }^{c} n=4$; values followed by the same letter in the same column are not significantly different at

$61095 \%$ confidence level. Statistical analysis of the different categories was performed separately. 
611 Table 2.

\begin{tabular}{|c|c|c|c|c|c|c|c|}
\hline Sample & $\begin{array}{c}\text { Specific } \\
\text { volume }^{\text {b }} \\
\mathrm{mL} / \mathrm{g}\end{array}$ & $\begin{array}{c}\text { Width/height } \\
\text { ratio }^{b} \\
\mathrm{~cm} / \mathrm{cm}\end{array}$ & Hardness $^{b}$ & $\begin{array}{c}\text { Cell area/ } \\
\text { Total area', } \\
\mathrm{cm}^{2} / \mathrm{cm}^{2}\end{array}$ & $\begin{array}{c}\text { Wall area/ } \\
\text { Total areac, } \\
\mathrm{cm}^{2} / \mathrm{cm}^{2}\end{array}$ & Cells $/ \mathrm{cm}^{2}$ & $\begin{array}{c}\text { Mean cell } \\
\text { area }^{\mathrm{c}} \\
\text { mm }^{2}\end{array}$ \\
\hline Control & $2.46 \pm 0.13 a$ & $1.80 \pm 0.10 \mathrm{a}$ & $2.61 \pm 0.31 \mathrm{a}$ & $0.397 \pm 0.099 a$ & $0.613 \pm 0.099 a$ & $299 \pm 101 a$ & $1.10 \pm 0.20 \mathrm{ab}$ \\
\hline WDS-5 & $2.31 \pm 0.13 a b$ & $1.74 \pm 0.06 \mathrm{a}$ & $2.51 \pm 0.29 \mathrm{a}$ & $0.351 \pm 0.059 a$ & $0.649 \pm 0.059 a$ & $282 \pm 37 a$ & $1.03 \pm 0.18 \mathrm{ab}$ \\
\hline WDS-10 & $2.38 \pm 0.09 a b$ & $1.89 \pm 0.12 \mathrm{a}$ & $2.67 \pm 0.13 \mathrm{ab}$ & $0.393 \pm 0.030 \mathrm{a}$ & $0.607 \pm 0.030 \mathrm{a}$ & $264 \pm 55 a$ & $1.32 \pm 0.26 \mathrm{a}$ \\
\hline WDS-15 & $2.35 \pm 0.05 a b$ & $1.67 \pm 0.29 \mathrm{a}$ & $3.09 \pm 0.30 \mathrm{bc}$ & $0.343 \pm 0.050 \mathrm{a}$ & $0.657 \pm 0.050 \mathrm{a}$ & $302 \pm 52 a$ & $0.95 \pm 0.17 \mathrm{~b}$ \\
\hline WDS-20 & $2.22 \pm 0.12 b$ & $1.68 \pm 0.24 \mathrm{a}$ & $3.18 \pm 0.25 \mathrm{c}$ & $0.350 \pm 0.053 a$ & $0.650 \pm 0.053 a$ & $274 \pm 51 \mathrm{a}$ & $1.20 \pm 0.24 \mathrm{ab}$ \\
\hline
\end{tabular}

612 Baread formulations WDS-5, WDS-10, WDS-15 and WDS-20: wheat dough with 5, 10, 15 and 20\% of sourdough inoculated with bifidobacteria,

613 respectively.

614 Mean, ${ }^{a} \mathrm{n}=6 ;{ }^{b} \mathrm{n}=12$; values followed by the same letter in the same column are not significantly different at $95 \%$ confidence level 
Table 3.

\begin{tabular}{lcccccc}
\hline Sample & \multicolumn{5}{c}{ Crust } & \multicolumn{3}{c}{ Crumb } \\
\cline { 2 - 7 } & \multicolumn{1}{c}{$\boldsymbol{L}^{*}$} & $\boldsymbol{C}^{*}$ & $\boldsymbol{h}^{*}$ & $\boldsymbol{L}^{*}$ & $\boldsymbol{C}^{*}$ & $\boldsymbol{h}^{*}$ \\
\hline Control & $49.2 \pm 4.0 \mathrm{ab}$ & $32.0 \pm 2.4 \mathrm{ab}$ & $64.3 \pm 2.9 \mathrm{abc}$ & $55.5 \pm 1.9 \mathrm{a}$ & $20.5 \pm 0.9 \mathrm{a}$ & $77.7 \pm 2.0 \mathrm{a}$ \\
WDS-5 & $50.0 \pm 2.0 \mathrm{a}$ & $33.0 \pm 1.4 \mathrm{a}$ & $65.3 \pm 2.1 \mathrm{a}$ & $58.4 \pm 1.4 \mathrm{~b}$ & $21.0 \pm 1.0 \mathrm{bc}$ & $77.5 \pm 1.5 \mathrm{a}$ \\
WDS-10 & $48.2 \pm 3.8 \mathrm{ab}$ & $33.1 \pm 2.9 \mathrm{a}$ & $64.6 \pm 3.1 \mathrm{ab}$ & $55.6 \pm 1.9 \mathrm{a}$ & $20.7 \pm 0.6 \mathrm{ab}$ & $76.5 \pm 1.4 \mathrm{~b}$ \\
WDS-15 & $46.9 \pm 5.1 \mathrm{ab}$ & $31.9 \pm 2.6 \mathrm{ab}$ & $62.7 \pm 4.2 \mathrm{bc}$ & $57.8 \pm 1.3 \mathrm{~b}$ & $21.2 \pm 0.7 \mathrm{c}$ & $77.1 \pm 1.1 \mathrm{ab}$ \\
WDS-20 & $46.3 \pm 3.4 \mathrm{~b}$ & $31.4 \pm 2.1 \mathrm{~b}$ & $62.3 \pm 2.8 \mathrm{c}$ & $57.8 \pm 1.7 \mathrm{~b}$ & $21.2 \pm 0.9 \mathrm{c}$ & $77.6 \pm 1.2 \mathrm{a}$
\end{tabular}

$616{ }^{\mathrm{a} B r e a d}$ formulations WDS-5, WDS-10, WDS-15 and WDS-20: wheat dough with 5, 10, 15 and 20\% of sourdough

617 inoculated with bifidobacteria, respectively.

$618{ }^{\mathrm{b}}$ Mean, $\mathrm{n}=18$; values followed by the same letter in the same column are not significantly different at $95 \%$

619 confidence level

620 
621Table 4.

\begin{tabular}{|c|c|c|c|c|c|c|}
\hline \multirow[t]{3}{*}{ Sample } & \multirow{3}{*}{$\begin{array}{c}\text { \% } \\
\text { Hydrolysis }\end{array}$} & \multicolumn{5}{|c|}{ myo-inositol phosphates ${ }^{\text {cd }}$} \\
\hline & & \multicolumn{5}{|c|}{$\mu \mathrm{mol} / \mathrm{g}$ of bread d.m. } \\
\hline & & Ins $_{6}$ & Ins $P_{5}$ & InsP $P_{4}$ & Ins $P_{3}$ & Ins $P_{6}+$ InsP $P_{5}$ \\
\hline Control & $22.2 \pm 5.9 \mathrm{a}$ & $7.62 \pm 0.58 \mathrm{a}$ & $1.25 \pm 0.04 \mathrm{a}$ & $0.80 \pm 0.08 a$ & $0.55 \pm 0.04 \mathrm{a}$ & $8.86 \pm 0.61 \mathrm{a}$ \\
\hline WDS-5 & $43.7 \pm 3.2 b$ & $5.51 \pm 0.31 b$ & $1.45 \pm 0.14 \mathrm{ab}$ & $1.76 \pm 0.13 \mathrm{~b}$ & $1.05 \pm 0.13 b$ & $6.96 \pm 0.18 b$ \\
\hline WDS-10 & $63.4 \pm 3.8 c$ & $3.58 \pm 0.37 c$ & $1.32 \pm 0.05 a$ & $2.43 \pm 0.34 c$ & $1.21 \pm 0.14 b$ & $4.91 \pm 0.42 c$ \\
\hline WDS-15 & $75.0 \pm 2.9 \mathrm{~d}$ & $2.44 \pm 0.28 \mathrm{~d}$ & $1.75 \pm 0.13 \mathrm{c}$ & $3.23 \pm 0.40$ de & $1.25 \pm 0.23 b$ & $4.19 \pm 0.39 d$ \\
\hline WDS-20 & $85.2 \pm 3.7 \mathrm{e}$ & $1.45 \pm 0.36 \mathrm{e}$ & $1.73 \pm 0.31 b c$ & $3.07 \pm 0.48 \mathrm{~d}$ & $1.25 \pm 0.19 b$ & $3.17 \pm 0.67 \mathrm{e}$ \\
\hline WDAcCS-20 & $79.8 \pm 0.7 d$ & $1.98 \pm 0.07 \mathrm{~d}$ & $2.02 \pm 0.18 d$ & $3.71 \pm 0.11 \mathrm{e}$ & $1.54 \pm 0.04 \mathrm{c}$ & $4.00 \pm 0.23 d$ \\
\hline
\end{tabular}

62 $\overline{2 B r e a d ~ f o r m u l a t i o n s ~ W D S-5, ~ W D S-10, ~ W D S-15 ~ a n d ~ W D S-20: ~ w h e a t ~ d o u g h ~ w i t h ~ 5, ~ 10, ~} 15$ and 20\% of sourdough 623noculated with bifidobacteria, respectively. WDAcCS-20: wheat dough with $20 \%$ acid control sourdough with 624ntibiotics.

$625^{b}$ Mean, $n=4$; values followed by the same letter in the same column are not significantly different at $95 \%$ confidence 626level

$627^{\mathrm{C}}$ Ins $P_{3}$ to Ins $P_{6}$ : myo-inositol phosphate containing 3-6 phosphates per inositol residue

628 d.m.: dry matter

629

630 
631

632

633
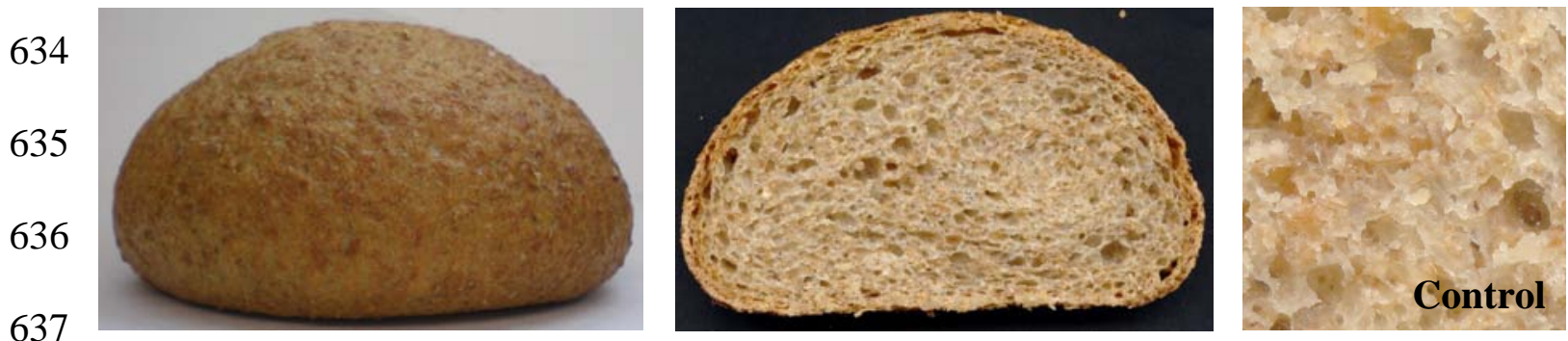

638
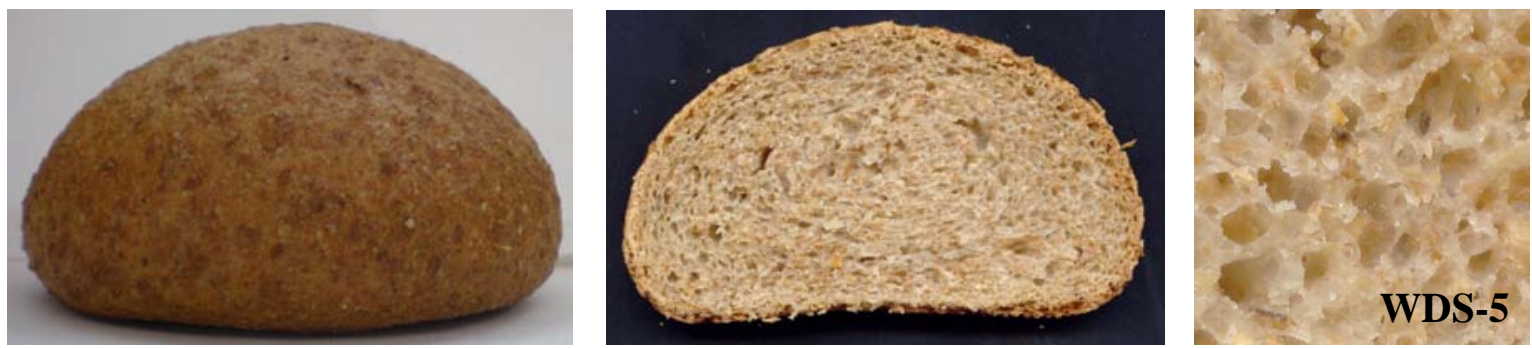

641
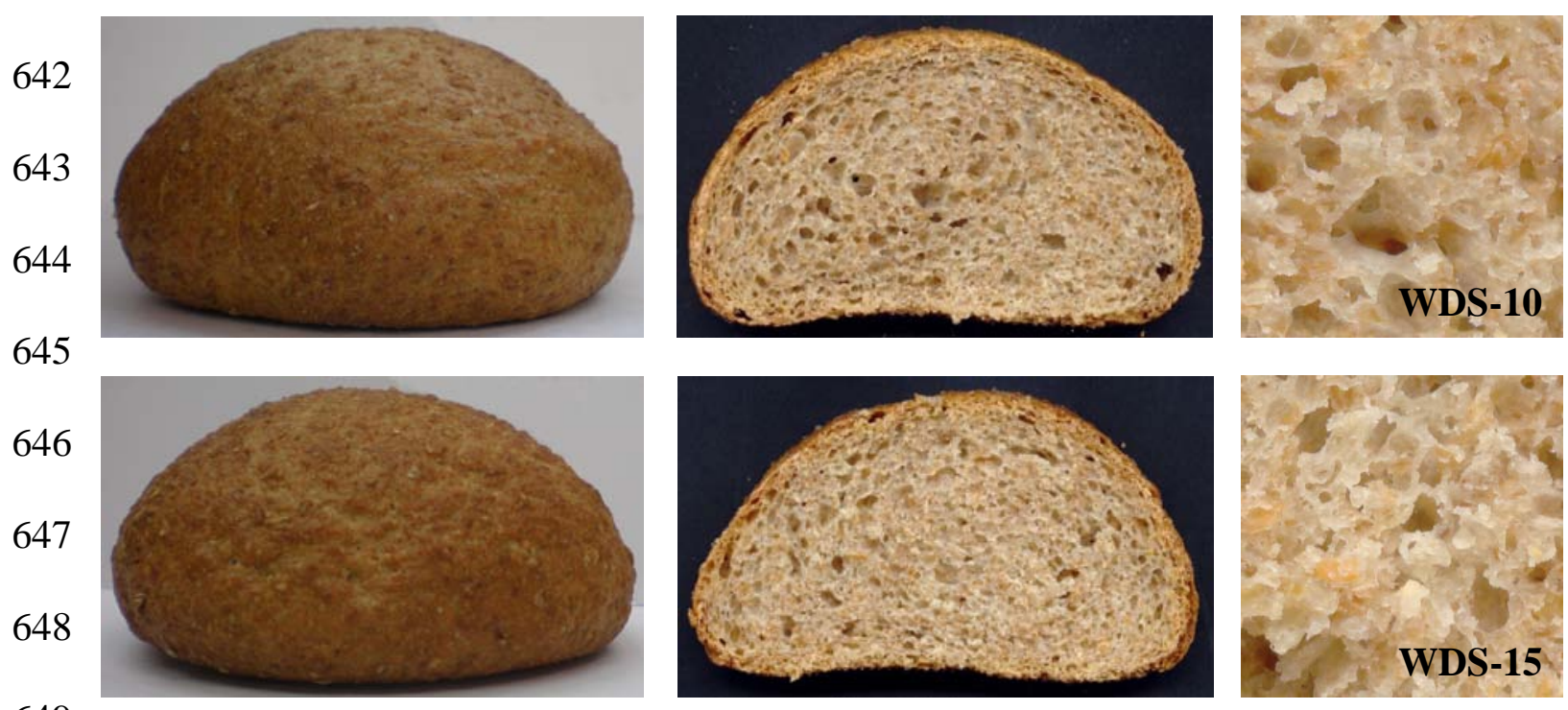

649

650

651
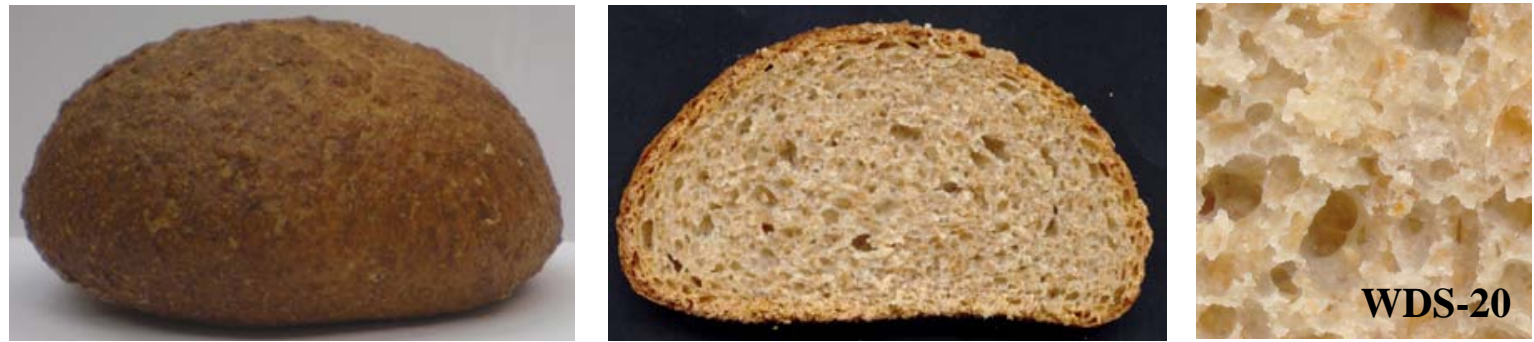

653

$654 \quad$ Figure 1.

655 
657

658

659

660

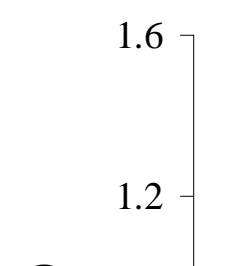

6

20

661

662

663

664

665

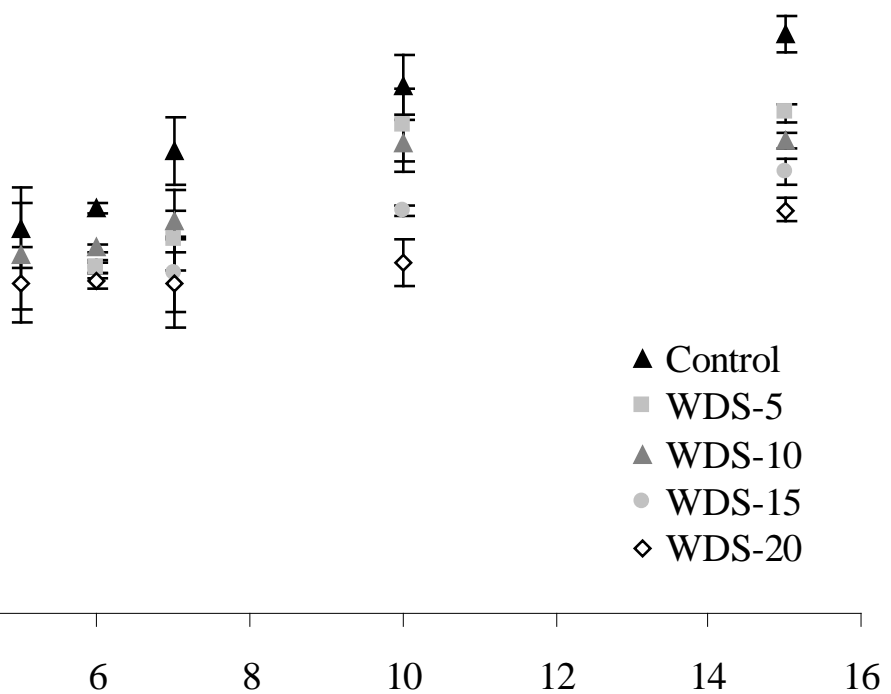

Time (days)

666

667 Figure 2.

668

669

670 